\title{
Betalains, total polyphenols, and antioxidant contents in red beetroot peel (Cylindra type)
}

\author{
MOH MOH ZIN* ㅁ, FRUZSINA BORDA, EDIT MÁRKI and \\ SZILVIA BÁNVÖLGYI
}

Department of Food Engineering, Faculty of Food Science, Szent István University, Budapest, Hungary

\section{CONFERENCE FULL PAPER}

Received: August 13, 2020 • Accepted: September 20, 2020

Published online: October 30, 2020

(C) 2020 The Author(s)

\begin{abstract}
Since significant percentage of fruits and vegetables go to waste during processing, investigation of how to improve the valuable products of extraction from the wastes is an undeniably effective way to save the planet. Beetroot (root, peel, and stalk) is a chief source of natural betalain color compounds and phenolic compounds with copious radical scavenging activity. The major emphasis of this work is to optimize process variables which are extraction time $(10-60 \mathrm{~min})$, operating temperature $\left(20-50{ }^{\circ} \mathrm{C}\right)$, and aqueous ethanol solvent with the concentration of $(25-75 \%)$ for effective extraction of valuable compounds such as betalains, total polyphenols, and antioxidant activity from beetroot peel. Spectrophotometric analysis was applied for quantification of those compounds. Amongst which, lowest solvent concentration (25\% v/v) together with the highest temperature $\left(50^{\circ} \mathrm{C}\right)$ and extraction time $(50 \mathrm{~min})$ brought yielded higher results. The process optimization was carried out using Design Expert (11.0.3) statistical software. Overall, it can be noted that extraction process can be improved by controlling operating time and temperature, avoiding unnecessary overuse of costly solvent.
\end{abstract}

\section{KEYWORDS}

betalains, phenolic, antioxidant, beetroot peel, ethanol, extraction

\footnotetext{
*Corresponding author. E-mail: zinlay.net.mm@gmail.com
} 


\section{INTRODUCTION}

Natural colorants such as carotenoids, anthocyanins, and betalains are noble health-promoting substituents of artificial dyes. Scavenging of those valuable compounds from agro-industrial wastes is always beneficial (Cserjési et al., 2011). Predominant sources of nitrogen containing betalain compounds are red colored vegetables such as opuntia, dragon fruit, swiss chard, pitaya and red beetroot (Akbar Hussain et al., 2018). Beetroot standing first in the list of interest by consumers is regarded as a rich antioxidant vegetable, accompanied with some other bioactive compounds such as betalains, ascorbic acid, carotenoids, phenolic acids, and flavonoids (Zin et al., 2020).

Betalains are the main compounds associated with the displayed red color of flowers, fruits and other plant tissues offering two color patterns which are yellow betaxanthin and red-violet betacyanin (zin et al., 2020). Betacyanin named as betanin contains phenolic and cyclic amine groups which strongly exhibits radical scavenging properties is chiefly applied in food industries (Anna et al., 2006). Unlike betacyanin, application of yellow betaxanthin as colorant is limited by its sensitivity (Cai et al., 2005). According to Kathiravan et al. (2015), betacyanin is more tolerant to reduce color than betaxanthin during storage.

Conventional solid-liquid extraction is based on solvation of solid materials with proper portion of solvent under heating or agitation. Herein, water, methanol-water, and ethanol-water are commonly used solvents in different ratios. Since betalains are sensitive to process conditions, extraction of betalains can be upgraded by adjusting $\mathrm{pH}$ (acidification) and processing temperature (Zin et al., 2020). Free sugar content in the matrix can be reduced via fermentation, thereby consequently raising the quantity of betalains (Delgado-Vargas et al., 2010). Czapski et al. (2009) explored that the correlation between red betacyanin and antioxidant is considerable, whereas yellow betaxanthin shows indescribable correlation. Phenolic compounds are predominantly found in all edible plants in different forms (conjugated ring structure and hydroxyl groups), possessing strong free radicals and ROS scavenging power (Manach et al., 2004).

Few reports for correlation between betaxanthin and betacyanin, total phenolic compounds (TPC) and antioxidant extracted from beetroot peel are available so far. Besides, process variables to improve the extraction of these compounds have hardly been considered in previous reports. The present study has paid attention mainly to the role of solvent in maximizing the recovery of these valuable compounds from the beetroot processing wastes.

\section{MATERIALS AND METHODS}

\section{Juice extraction}

Beetroot peel extracts were prepared as follows: fresh beetroots (Cylindra type) were processed right away after harvesting. Beetroots were cleaned before being peeled manually. Afterwards, the peels were grinded by pulverizer to assist the mass transfer process during extraction. Pulp (15) $\mathrm{g}$ was weighed and mixed with $150 \mathrm{~mL}$ of aqueous ethanol solvent $(25,50,75 \% \mathrm{v} / \mathrm{v}$ ethanol). Single-stage batch extraction was carried out for $(10,35,60 \mathrm{~min})$ at $\left(20,35,50{ }^{\circ} \mathrm{C}\right)$ by double wall jacket laboratory extractor equipped with YELLOWLINE OST 20 digital stirrer. The clear supernatant was achieved by centrifugation at $6,000 \mathrm{rpm}$ for $25 \mathrm{~min}$ prior to spectrophotometric analysis. 


\section{Spectrophotometric analysis}

Color compounds, total polyphenol content, and antioxidant assays were performed by spectrophotometer (Genesys $5 \mathrm{UV}$-visible). Samples were diluted in appropriate ratios with distilled water for each analysis. For color compound detections, the absorbance was recorded at $480 \mathrm{~nm}$ for betaxanthin compound and $535 \mathrm{~nm}$ for betacyanin compound respectively. By then, concentrations of the specific betalain compounds were calculated as follows:

$$
\text { Betalain }=\frac{A \cdot M W \cdot D F \cdot 1000}{\varepsilon \cdot L}\left(\mathrm{mg} \mathrm{L}^{-1}\right)
$$

where $A$ is the absorbance; $M W$ is the molecular weight; $D F$ is the dilution factor; $\varepsilon$ is the molar extinction coefficient and $L$ is the path length. Molecular weight and molar extinction coefficient for betaxanthin are $(M W=308 \mathrm{~g} / \mathrm{mol}$ and $\varepsilon=48,000 \mathrm{~L} /(\mathrm{mol} \cdot \mathrm{cm})$ in water), and for betacyanin $(M W=550 \mathrm{~g} / \mathrm{mol}$ and $\varepsilon=60,000 \mathrm{~L} /(\mathrm{mol} \cdot \mathrm{cm})$ in water) (Pandey et al., 2018; Ravichandran et al., 2013). Analysis for TPC contents of each sample was performed by FolinCiocalteu method. Quantification of TPC was completed at $760 \mathrm{~nm}$ and calculated as follows:

$$
\mathrm{TPC}=\frac{A \cdot 2500 \cdot D F}{S \cdot a}\left(\mathrm{mg} \mathrm{GAE} \mathrm{L}^{-1}\right),
$$

whereby: $A$ - measured absorbance; $D F$ - dilution factor; $S$ - amount of sample; a - slope of calibration curve; GAE - gallic acid was used as a standard for calibration (Bueno et al., 2012). Antioxidant capacity was determined by Ferric reducing antioxidant power (FRAP) method as described by Benzie and Devaki (2018) with some modification and the absorbance was recorded at $593 \mathrm{~nm}$. Ascorbic acid (ASE) was applied as a standard for calibration and expressed as ascorbic acid equivalent. The calculation was done using the following equation:

$$
\mathrm{AA}=\frac{A \cdot 1550 \cdot D F}{S \cdot a}\left(\mathrm{mg} \mathrm{ASE} \mathrm{L}{ }^{-1}\right)
$$

Where $A$ - absorbance; $D F$ - dilution factor; $S$ - amount of sample; a - slope of calibration curve. The measurements of both TPC and Antioxidant were triplicated under the same conditions.

\section{RESULTS AND DISCUSSIONS}

Relationship between responses and independent variables was investigated by choosing central composite design (CCD) of Design Expert Software version 11.0.3 for response surface methodology (RSM) performance. The response is well modeled by a quadratic function of independent variables so that the approximating function is the second-order model:

$$
y=\beta_{0}+\sum_{i=1}^{k} \beta_{i} x_{i}+\sum_{i=1}^{k} \beta_{i i} x_{i i}^{2}+\sum \sum_{i<j} \beta_{i j} x_{i} x_{j}+\varepsilon
$$

Table 1 shows ANOVA for the quadratic model with square root transform. As can be seen in the table, lack of fit test is not significant for each response. $R$-squared values are not satisfactory for the dependent variables; however, the model can be regarded as significant from the overall 
Table 1. Analysis of Variance for the second-order quadratic function

\begin{tabular}{|c|c|c|c|c|c|c|c|c|c|}
\hline \multirow[b]{2}{*}{ Source } & \multirow[b]{2}{*}{ DF } & \multicolumn{4}{|c|}{ Estimated coefficient } & \multicolumn{4}{|c|}{ F Value } \\
\hline & & Betaxanthin & Betacyanin & IPC & Antioxidant & Betaxanthin & Betacyanin & TPC & Antioxidant \\
\hline Model & 4 & 9.11 & 12.07 & 16.23 & 24.30 & $6.04^{*}$ & $4.56^{*}$ & $5.69 *$ & $4.55^{*}$ \\
\hline A & 1 & 0.71 & 0.95 & 1.41 & 1.92 & $10.37^{*}$ & $9.78^{*}$ & $6.10^{*}$ & $7.96^{*}$ \\
\hline B & 1 & 0.18 & 0.01 & 2.09 & 1.45 & 0.67 & 0.002 & $13.44^{*}$ & $4.52^{*}$ \\
\hline $\mathrm{C}$ & 1 & -0.49 & -0.57 & 0.00 & -0.32 & $5.02 *$ & 3.54 & 0.00 & 0.22 \\
\hline$A^{2}$ & 1 & -0.89 & -0.95 & - & -2.26 & $8.09 *$ & $4.91^{*}$ & - & $5.49^{*}$ \\
\hline $\mathrm{C}^{2}$ & 1 & - & - & -1.44 & - & - & & 3.22 & - \\
\hline Residual & 15 & 7.27 & 13.78 & 48.56 & 69.47 & & & & \\
\hline Lack of Fit (Sum of Square) & 10 & 3.75 & 8.48 & 23.73 & 22.39 & & & & \\
\hline Pure Error (Sum of Square) & 5 & 3.51 & 5.30 & 24.84 & 47.08 & & & & \\
\hline Cor Total & 19 & 18.96 & 30.52 & 122.25 & 153.76 & & & & \\
\hline Std. Dev. & & 0.70 & 0.96 & 1.80 & 2.15 & & & & \\
\hline Mean & & 8.67 & 11.60 & 15.51 & 23.17 & & & & \\
\hline C.V. \% & & 8.03 & 8.26 & 11.60 & 9.29 & & & & \\
\hline
\end{tabular}

*Significant at "Prob > F" less than 0.05 . 
point of view considering $F$-test, standard deviation, mean, and coefficient of variation. $P$-value is lower than 0.05 in extraction time for all responses revealing its significant effects to all outputs. Temperature is significant for total phenolic compound (TPC) and antioxidant, whereas solvent concentration is significant for betalains, individually.

The model operated the following regression equations for each dependent variable:

$$
\begin{aligned}
& \text { Sqrt }(\text { Betaxanthin })=+6.951+0.127 * A+0.012 * B-0.019 * C-0.001 * A^{2} \\
& \operatorname{Sqrt}(\text { Betacyanin })=+9.997+0.144^{*} A+0.001 * B-0.023 * C-0.002 * A^{2} \\
& \operatorname{Sqrt}(\mathrm{TPC})=+3.616+0.056^{*} A+0.139 * B+0.231 * C-0.002 * C^{2} \\
& \operatorname{Sqrt}(\text { Antioxidant })=+14.447+0.329 * A+0.097 * B-0.013 * C-0.004 * A^{2}
\end{aligned}
$$

Where $A$ means extraction time, $B$ means temperature, and $C$ represents solution concentration.

According to model's suggestion, twenty experimental runs were implemented under three different process variables: time $(10-60 \mathrm{~min})$, temperature $\left(20-50{ }^{\circ} \mathrm{C}\right)$, and aqueous ethanol solvent $(25-75 \% \mathrm{v} / \mathrm{v})$ respectively, which were depicted in Table 2 accompanying their corresponding responses. As we can see in the table, the minimum and maximum yields of respective

Table 2. Experimental scheme and results

\begin{tabular}{lccccccc}
\hline & \multicolumn{3}{c}{ Process Variable } & & \multicolumn{4}{c}{ Response } \\
\cline { 2 - 5 } \cline { 6 - 8 } Run & $\begin{array}{c}\text { Time } \\
(\mathrm{min})\end{array}$ & $\begin{array}{c}\text { Temperature } \\
\left({ }^{\circ} \mathrm{C}\right)\end{array}$ & $\begin{array}{c}\text { Solvent } \\
(\%)\end{array}$ & $\begin{array}{c}\text { Betaxanthin } \\
\left(\mathrm{mg} \mathrm{L}^{-1}\right)\end{array}$ & $\begin{array}{c}\text { Betacyanin } \\
\left(\mathrm{mg} \mathrm{L}^{-1}\right)\end{array}$ & $\begin{array}{c}\text { TPC } \\
\left(\mathrm{mg} \mathrm{L}^{-1}\right)\end{array}$ & $\begin{array}{c}\text { Antioxidant } \\
\left(\mathrm{mg} \mathrm{L}^{-1}\right)\end{array}$ \\
\hline 1 & 10 & 20 & 75 & 46.29 & 85.31 & 104.28 & 347.94 \\
2 & 10 & 20 & 25 & 46.46 & 84.46 & 100.06 & 267.37 \\
3 & 35 & 35 & 50 & 63.91 & 115.62 & 267.76 & 488.34 \\
4 & 60 & 50 & 75 & 68.62 & 122.22 & 325.07 & 548.41 \\
5 & 35 & 20 & 50 & 90.52 & 165.24 & 304.40 & 567.45 \\
6 & 35 & 35 & 50 & 112.68 & 194.33 & 260.71 & 866.81 \\
7 & 35 & 35 & 50 & 83.93 & 145.81 & 266.82 & 492.74 \\
8 & 10 & 50 & 75 & 60.66 & 110.00 & 279.03 & 481.02 \\
9 & 60 & 20 & 75 & 76.23 & 148.13 & 193.54 & 498.11 \\
10 & 35 & 35 & 75 & 59.97 & 109.39 & 228.30 & 607.50 \\
11 & 60 & 20 & 25 & 85.73 & 163.41 & 189.78 & 506.90 \\
12 & 60 & 35 & 50 & 75.97 & 141.29 & 330.70 & 622.64 \\
13 & 10 & 35 & 50 & 57.66 & 108.78 & 193.54 & 459.04 \\
14 & 35 & 35 & 50 & 88.55 & 149.11 & 334.46 & 659.26 \\
15 & 60 & 50 & 25 & 94.03 & 155.34 & 295.00 & 709.07 \\
16 & 35 & 35 & 25 & 98.22 & 172.58 & 281.85 & 695.89 \\
17 & 35 & 50 & 50 & 73.32 & 116.84 & 327.88 & 570.87 \\
18 & 35 & 35 & 50 & 82.22 & 143.12 & 133.88 & 450.74 \\
19 & 10 & 50 & 25 & 73.92 & 133.10 & 262.12 & 495.67 \\
20 & 35 & 35 & 50 & 83.84 & 157.18 & 255.54 & 558.18 \\
\hline
\end{tabular}


compounds were as follows: $46.29-112.68 \mathrm{mg} \mathrm{L}^{-1}$ (betaxanthin), 84.46-194.33 $\mathrm{mg} \mathrm{L}^{-1}$ (betacyanin), 100.06-334.46 $\mathrm{mg} \mathrm{L}^{-1}$ (TPC), and 267.37-866.81 $\mathrm{mg} \mathrm{L}^{-1}$ (antioxidant).

\section{Correlational effects of time and temperature}

Contour diagrams (Fig. 1(a), (d), (g), and (j)) show the interaction effects of process time and temperature on betaxanthin, betacyanin, TPC, and antioxidant capacity whilst ethanol solvent (\%) was fixed at the center point $(50 \% \mathrm{v} / \mathrm{v})$. Yields of betalains, TPC, and antioxidant capacity were elevated with extending the processing time (from $30 \mathrm{~min}$ to $60 \mathrm{~min}$ ) as suggested by the model that is the experimental parameter of operation time is significant for all outcomes. This finding is matched with the observation of Winitsorn et al. (2008) in which the authors declared that solute concentration in solvent phase depends only on extraction time. This is because enough time to reach mass and heat transfer equilibrium is required in solid-liquid extraction (Sattler and Feindt, 1995). Betalains and antioxidant improved a bit with extended operating time, TPC content had, however, increased dramatically. Aside from the extraction time, TPC was found to be affected by temperature as well. In the same vein, a slight improvement in antioxidant capacity was observed with increasing temperature, which is in accordance with the observation of Pedreno and Escribano (2001). Regarding temperature, there are no significant changes in the amount of betalains. As for TPC, both time and temperature had positive effects on the yield giving the highest TPC content at maximum operating time $(60 \mathrm{~min})$ and temperature $\left(50{ }^{\circ} \mathrm{C}\right)$. The possible explanation here is that the combination of longer extraction time and higher temperature might have softened the plant tissues accelerating the shift of phenolic compounds to the extraction medium (Kushwaha et al., 2018).

\section{Correlational effects of temperature and ethanol solvent percent}

With regard to fixed extraction time $(35 \mathrm{~min})$, the interaction of temperature and ethanol solvent percent were probed for all responses (Fig. 1(b), (e), (h), and (k)). The contour plots proved that the effect of neither extraction temperature nor solvent on all outputs, except TPC, was found to be noteworthy. It means that the experimental parameters of these independent variables were not efficient to judge their effectiveness in accordance with dependent responses i.e., betalains and antioxidant. Here again, for TPC content, the combined effect of operating temperature and solvent was remarkable where the improvement of TPC content was found to be correlated with higher operating temperature and solvent concentration (Fig. 1(h)). Over $3,000 \mathrm{mg} \mathrm{L}^{-1}$ of phenolic compounds was obtained when the temperature was increased up to $45{ }^{\circ} \mathrm{C}$ and solvent concentration around $50 \% \mathrm{v} / \mathrm{v}$. This might have been due to possible earlier explanation discussed in the section of time and temperature interaction. In addition, the solubility of the solute to be dissolved in the solvent is correlated with the temperature of the solvent (Sattler and Feindt, 1995). Although the calculated $P$-value from the model is greater than 0.05 in the case of solvent concentration, there is a decline in TPC amount as the concentration of aqueous ethanol was higher up to $50 \%$. It could be concluded that the extraction process reached the highest limit so that no more solvent is necessary to draw the compounds out of the plant tissues. The concentration gradient that affects the diffusivity becomes more significant with increasing solvent concentration and stops when the equilibrium is reached (Cacace and Mazza, 2003). 

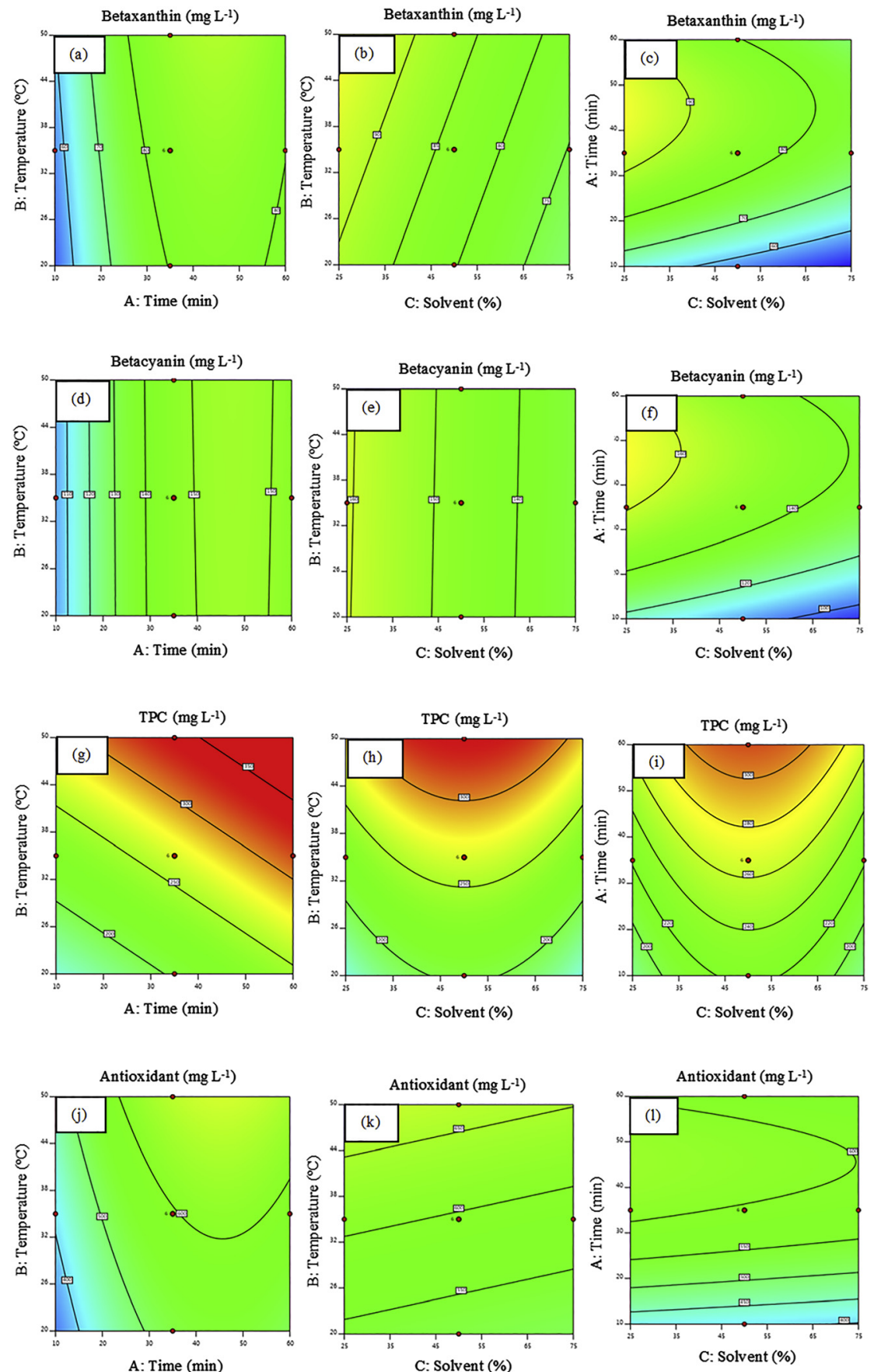

Fig. 1. Contour plots for betalains, total phenolic, and antioxidant contents in beetroot peel extracts 


\section{Correlational effects of time and solvent concentration}

Fig. 1(c), (f), (i) and (l) exhibit the combined effect of time and solvent concentration on each dependent variable. The contour plots for betaxanthin and betacyanin reveal that higher operation time (over $45 \mathrm{~min})$ accompanied with low concentration of solvent $(<35 \% \mathrm{w} / \mathrm{v})$ provided the better yield of the pigments (Fig. 1(c) and (f)). It is in accordance with the observation of (Kushwaha et al., 2018) who claimed that the higher yield of betalain pigments was achieved with low concentration of solvent. It means that lower concentration of solvent requires greater time and temperature due to the process needs to be driven to accomplish the transfer of plant materials to the extraction medium (Sanchez-Gonzalez et al., 2013). Therefore, the efficiency of extraction can be boosted by raising process time and temperature with minimum solvent concentration. Notably, TPC content became greater with time when the temperature was fixed at $35^{\circ} \mathrm{C}$ though solvent concentration affected the yield to some extent which is in contrast to the finding of Pandey et al. (2018) who pointed out that no benefit in yield resulted with increasing time. The possible reason here is that a different genotype of raw materials can vary the effectiveness of process variables on the responses (Sawicki et al., 2016). As shown in Fig. 1(1), it is evident that antioxidant was independent on aqueous ethanol concentration though a bit improvement in quantity was observed in higher extraction time. The possible explanation might be the same with betalains, since the model estimated that betalain is correlated with antioxidant activity in the positive term, i.e., 0.8.
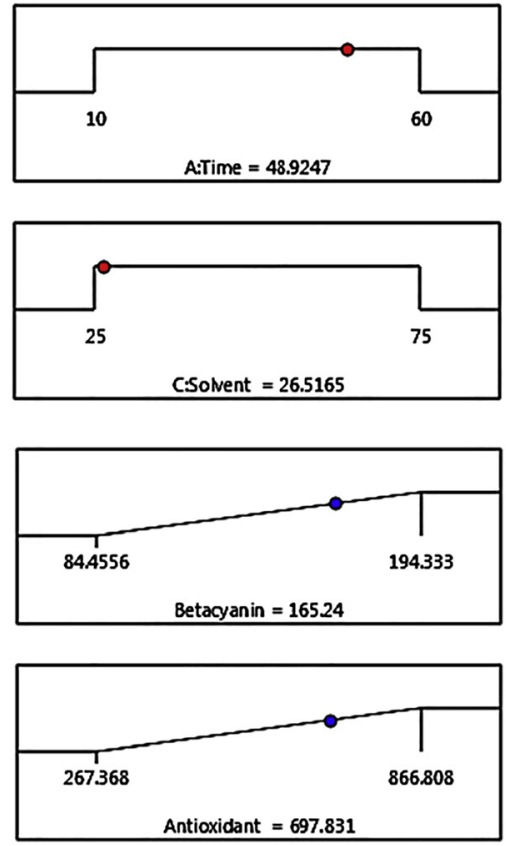
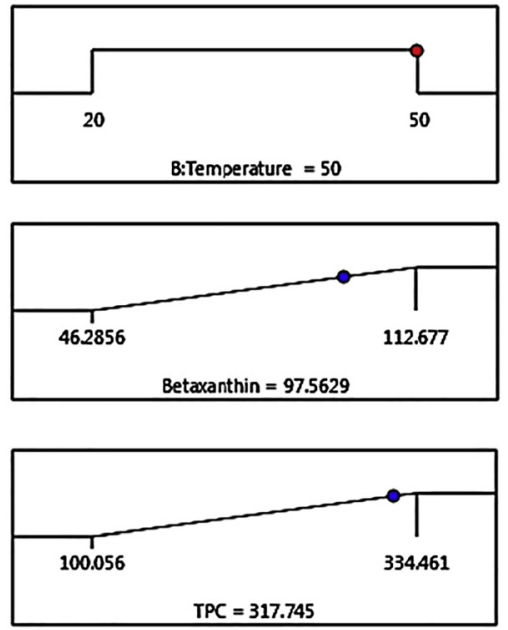

Desirability $=0.820$
Solution 1 out of 34

Fig. 2. Optimum condition of process variables for corresponding responses 


\section{CONCLUSION}

The optimum condition of process variables was chosen by the model depending on the overall highest yield of betaxanthin $\left(97.56 \mathrm{mg} \mathrm{L}^{-1}\right)$, betacyanin $\left(165.24 \mathrm{mg} \mathrm{L}^{-1}\right)$, phenolic compounds $\left(317.75 \mathrm{mg} \mathrm{L}^{-1}\right)$, and antiradical activity $\left(697.83 \mathrm{mg} \mathrm{L}^{-1}\right)$ that is with the desirability of 0.82 (Fig. 2). In our experiment, the interactions of time, temperature, and solvent concentration were accomplished in order to supply the improvement of valuable compounds extraction. As the model suggested solvent concentration to the lowest, further investigation could be carried out with ethanol solvent concentration keeping it lower than $25 \% \mathrm{v} / \mathrm{v}$. Ultimately, approaching to the highest outcome of the specific compounds can be effective by the application of central composite design so that these compounds applications can be extended to different fields with minimal processing costs.

\section{NOMENCLATURE}

$\begin{array}{ll}\text { A } & \text { sample absorbance } \\ \text { a } & \text { slope of calibration curve } \\ A A & \text { antioxidant activity }\left(\mathrm{mg} \mathrm{L}^{-1}\right) \\ A S E & \text { ascorbic acid equivalent } \\ \text { DF } & \text { dilution factor } \\ \text { FRAP } & \text { Ferric reducing antioxidant power method } \\ \text { GAE } & \text { gallic acid equivalent } \\ L & \text { path length }(\mathrm{cm}) \\ M W & \text { molecular weight }(\mathrm{g} / \mathrm{mol}) \\ S & \text { amount of sample }(\mu \mathrm{L}) \\ \text { TPC } & \text { concentration of total phenolic compounds }\left(\mathrm{mg} \mathrm{L}^{-1}\right) \\ \varepsilon & \text { molar extinction coefficient }(\mathrm{L} /(\mathrm{mol} \cdot \mathrm{cm}))\end{array}$

\section{REFERENCES}

Akbar Hussain, E., Sadiq, Z., and Zia-Ul-Haq, M. (2018). Sources of betalains. In: Betalains: biomolecular aspects. Springer, Cham, pp. 15-32.

Anna, G.S., Henryk, S., and Paulina, M. (2006). Betanin, the main pigment of red beet- molecular origin of its expectionally high free radical scavenging activity. Food Additives and Contaminants 23(11): 10791087.

Benzie, I.F.F. and Devaki, M. (2018). Measurement of antioxidant activity and capacity: recent trends of applications, 1st ed. John Wiley \& Sons Publishers, pp. 77-106.

Bueno, F.G., Machareth, M.A.D., Panizzon, G.P., Lopes, G.C., Mello, J.C.P., and Leite-Mello, E.V.S. (2012). Development of a uv/vis spectrophotometric method for analysis of total polyphenols from Caesalpinia peltophoroides benth. Química Nova 35(4): 822-826.

Cacace, J.E. and Mazza, G. (2003). Mass transfer process during extraction of phenolic compounds from milled berries. Journal of Food Engineering 59(4): 379-389. 
Cai, Y.Z., Sun, M., and Corke, H. (2005). Characterization and application of betalain pigments from plants of the Amaranthaceae. Trends Food Science and Technology 16(9): 370-376.

Cserjési, P., Bélafi-Bakó, K., Csanádi, Z., Beszédes, S., and Hodúr, C. (2011). Simultaneous recovery of pectin and colorants from solid agro-wastes formed in processing of colorful berries. Progress in Agricultural Engineering Sciences 7(1): 65-80.

Czapski, J., Mikołajczyk, K., and Kaczmarek, M. (2009). Relationship between antioxidant capacity of red beet juice and contents of its betalain pigments. Polish Journal of Food and Nutrition Sciences 59(2): 119-122.

Delgado-Vargas, F., Jimenez, A.R., and Paredes-Lopez, O. (2000). Natural pigments: carotenoids, anthocyanins, and betalains - characteristics, biosynthesis, processing, and stability. Critical Reviews In Food Science and Nutrition 40(3): 173-289.

Kathiravan, T., Nadanasabapathi, S., and Kumar, R. (2015). Pigments and antioxidant activity of optimized ready-to-drink (RTD) beetroot (Beta vulgaris L.) - passion fruit (Passiflora edulis var. flavicarpa) juice blend. The Croatian Journal of Food Science and Technology 7(1): 9-21.

Kushwaha, R., Kumar, V., Vyas, G., and Kaur, J. (2018). Optimization of different variable for eco-friendly extraction of betalains and phytochemicals from beetroot pomace. Waste Biomass Valor 9: 1485-1494.

Manach, C., Scalbert, A., Morand, C., Rémésy, C., and Jiménez, L. (2004). Polyphenols: food sources and bioavailability. American Journal of Clinical Nutrition 79: 727-747.

Pandey, G., Pandey, V., Pandey, P.R., and Thomas, G. (2018). Effect of extraction solvent temperature on betalain content, phenolic content, antioxidant activity and stability of beetroot (Beta Vulgaris L.) power under different storage conditions. Plant Archives 18(2): 1623-1627.

Pedreno, M.A. and Escribano, J. (2001). Correlation between antiradical activity and stability of betanine from Beta vulgaris $L$ roots under different $\mathrm{pH}$, temperature and light conditions. Journal of the Science of Food and Agriculture 81: 627-631.

Ravichandran, K., Saw, N.M.M.T., Mohdaly, A.A.A., Gabr, A.M.M., Kastell, A., Riedel, H., Cai, Z., Knorr, D., and Smetanska, I. (2013). Impact of processing of red beet on betalain content and antioxidant activity. Food Research International 50(2): 670-675.

Sanchez-Gonzalez, N., Jaime-Fonseca, M.R., Martin-Martinez, E.S., and Zepeda, L.G. (2013). Extraction, stability, and separation of betalains from opuntia joconostle cv. using response surface methodology. Journal of Agricultural and Food Chemistry 61(49): 11995-12004.

Sattler, K. and Feindt, H.J. (1995). Thermal separation process: Principles and design. Prof. H. Weinheim, CCNY, pp. 393-470.

Sawicki, T., Bączek, N., and Wiczkowski, W. (2016). Betalain profile, content and antioxidant capacity of red beetroot dependent on the genotype and root part. Journal of Functional Foods 27: 249-261.

Winitsorn, A., Douglas, P.L., Douglas, S., Pongampai, S., and Teppaitoon, W. (2008). Modeling the extraction of valuable substances from natural plants using solid-liquid extraction. Chemical Engineering Communications 195(11): 1457-1464.

Zin, M.M., Anucha, C.B., and Bánvölgyi, Sz. (2020). Recovery of phytochemicals via electromagnetic irradiation (microwave-assisted-extraction): Betalain and phenolic compounds in perspective. Foods 9(7): 918.

Open Access. This is an open-access article distributed under the terms of the Creative Commons Attribution 4.0 International License (https://creativecommons.org/licenses/by/4.0/), which permits unrestricted use, distribution, and reproduction in any medium, provided the original author and source are credited, a link to the CC License is provided, and changes - if any - are indicated. (SID_1) 